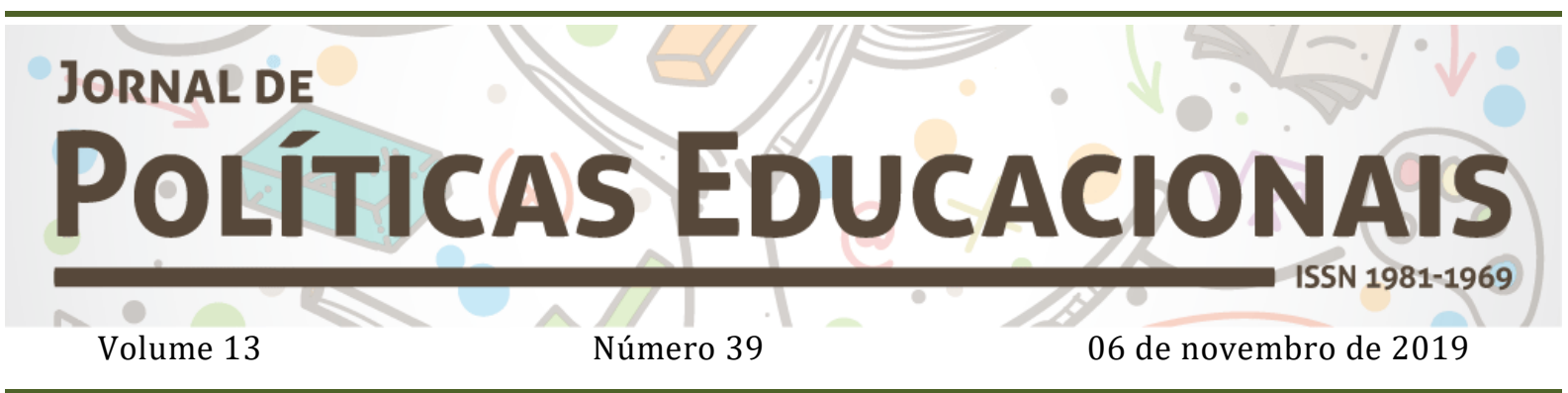

\title{
Condições de trabalho docente no Brasil: ensaio sobre a desvalorização na educação básica
}

\section{Conditions of teaching work in Brazil: test on devaluation in basic education}

\section{Condiciones de trabajo docente en Brasil: ensayo sobre la desvalorización en la educación básica}

\author{
Osni Oliveira Noberto da Silva ${ }^{1}$ \\ Theresinha Guimarães Miranda ${ }^{2}$ \\ Miguel Angel Garcia Bordas ${ }^{3}$
}

Citação: SILVA, O.O.N. da; MIRANDA, T. G; BORDAS, M.A.G. Condições de trabalho docente no Brasil: ensaio sobre a desvalorização na educação básica. Jornal de Políticas Educacionais. V. 13, n. 39. Novembro de 2019.

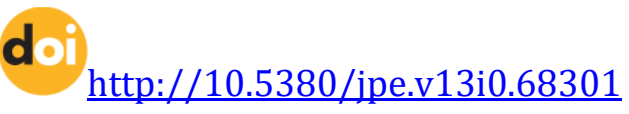

Resumo: 0 objetivo deste artigo foi discutir a desvalorização dos docentes brasileiros, que trabalham na educação básica, a partir de uma análise das condições de trabalho docente, os antecedentes históricos, o

\footnotetext{
1 Mestre e Doutorando em Educação pela Universidade Federal da Bahia (UFBA). Professor do Departamento de Ciências Humanas, Campus IV, da Universidade do Estado da Bahia (UNEB). Líder do Grupo de estudos, pesquisa e extensão em Educação Especial e Educação Física adaptada (GEPEFA) e integrante do Grupo de estudos sobre Educação Inclusiva e Necessidades Educacionais Especiais. Orcid: http://orcid.org/0000-0001-5028-0889. E-mail: osni_edfisica@yahoo.com

${ }^{2}$ Doutora em Educação pela Universidade de São Paulo, com pós-doutorado pela Umeå University, Suécia. Professora do Programa de Pós-graduação em Educação da Universidade Federal da Bahia (UFBA). Integrante do Grupo de estudos sobre Educação Inclusiva e Necessidades Educacionais Especiais (GEINE). Orcid: http://orcid.org/0000-0002-7762-7739. E-mail: tmiranda@ufba.br

3 Doutor em Filosofia pela Universidad Complutense de Madrid, com pós-doutorado pela Universitat Autònoma de Barcelona, Espanha. Professor do Programa de Pós-graduação em Educação da Universidade Federal da Bahia (UFBA). Integrante do Grupo de estudos sobre Educação Inclusiva e Necessidades Educacionais Especiais (GEINE). Orcid: http://orcid.org/0000-0001-5970-9581. E-mail: magbordas@gmail.com
} 
arcabouço legal e as influências do neoliberalismo nas políticas de Estado. 0 que podemos observar nas discussões com os autores e os dados apresentados é que existe uma defasagem entre o salário dos professores da educação básica no Brasil e a média dos profissionais das outras áreas. Há notáveis avanços na legislação educacional brasileira, com vistas à valorização do magistério e discussões sobre como fazer essa valorização, na qual sempre o salário entra na discussão como elemento central. Além disso, foi possível inferir que existe uma relação direta entre a qualidade do salário dos professores e sua valorização perante a sociedade, gerando efeitos psicossociais positivos para eles, como satisfação, motivação e consequentemente afetando diretamente na qualidade do trabalho executado e na melhoria da educação de forma geral. Assim, os professores e entidades representativas devem manter a reivindicação da continua valorização profissional perante a sociedade, resgatando o interesse que outrora existia nos jovens em ser professor. Paralelamente é importante que mais textos acadêmicos como este precisam ser produzidos, inclusive com estudos de campo, por se tratar de um tema de extrema relevância para o desenvolvimento de qualquer nação.

Palavras-chave: Trabalho docente; Políticas educacionais; Neoliberalismo.

\section{Abstract}

The aim of this paper was to discuss the devaluation of Brazilian teachers who work in Basic Education, from an analysis of the teaching work conditions, the historical background, the legal framework and the influences of neoliberalism on state policies. What we can observe in the discussions with the authors and the data presented is that there is a gap between the salary of basic education teachers in Brazil and the average of professionals from other areas. There are remarkable advances in Brazilian educational legislation, with a view to valuing the teaching profession and discussions on how to make this appreciation, where salary always enters the discussion as a central element. In addition, it was possible to infer that there is a direct relationship between the quality of teachers' salary and its value to society, generating positive psychosocial effects for them, such as satisfaction, motivation and consequently directly affecting the quality of the work performed and the improvement of education in general. Thus, teachers and representative entities should maintain the claim of continuing professional appreciation towards society, rescuing the interest that formerly existed in young people to be teachers. At the same time, it is important that more academic texts such as this one need to be produced, including field studies, as this is an extremely relevant subject for the development of any nation.

Keywords: Teaching work; Educational policies; Neoliberalism.

\section{Resumen}

El objetivo de este trabajo fue discutir la devaluación de los docentes brasileños que trabajan en Educación Básica, a partir de un análisis de las condiciones de trabajo docente, los antecedentes históricos, el marco legal y las influencias del neoliberalismo en las políticas estatales. Lo que podemos observar en las discusiones con los autores y los datos presentados es que existe una brecha entre el salario de los docentes de educación básica en Brasil y el promedio de profesionales de otras áreas. Hay avances notables en la legislación educativa brasileña, con miras a valorar la profesión docente y las discusiones sobre cómo hacer esta apreciación, donde el salario siempre entra en la discusión como un elemento central. Además, fue posible inferir que existe una relación directa entre la calidad del salario de los docentes y su valor para la sociedad, generando efectos psicosociales positivos para ellos, como la satisfacción, la motivación y, en consecuencia, afectando directamente la calidad del trabajo realizado y la mejora de la educación de forma general Por lo tanto, los maestros y las entidades representativas deben mantener el reclamo de la continua apreciación profesional hacia la sociedad, rescatando el interés que antes existía en los jóvenes para ser maestros. Al mismo tiempo, es importante que se produzcan más textos académicos como este, incluidos los estudios de campo, ya que este es un tema extremadamente relevante para el desarrollo de cualquier nación.

Palabras clave: Trabajo docente; Políticas educativas; El neoliberalismo.

\section{Introdução}


Este ensaio é parte integrante de discussões produzidas em pesquisa de doutorado ligada ao Grupo de Estudos sobre Educação Inclusiva e Necessidades Educacionais Especiais (GEINE), desenvolvido pelo Programa de Pós-graduação em Educação na Faculdade de Educação da Universidade Federal da Bahia (PPGE/FACED/UFBA), financiado por bolsa de estudos do Programa de Apoio à Capacitação de Docentes (PACDT) da Universidade do Estado da Bahia (UNEB).

0 foco da discussão do presente texto diz respeito às condições de trabalho dos professores da educação básica no Brasil, especificamente tendo como foco de análise a desvalorização salarial da categoria docente, que vem ocorrendo gradativamente nos últimos anos.

De acordo com Lancillotti (2010), o trabalho docente tem como objetivo principal ensinar um determinado conhecimento a alguém. Além disso, a mesma autora explica que o professor tem a responsabilidade em que "toma por objeto a formação cultural do aluno, o que compreende sua formação intelectual, moral e física; e é exercida pelo recurso a meios de trabalho especializados (conteúdos, recursos científicos técnicos, espaço físico)” (pág 85).

De acordo com os estudos de Lira (2013), mesmo com sua importância indiscutível em qualquer sociedade, o trabalho do professor vem sendo, nos últimos anos, objeto de discussão e investigação em seus diversos aspectos, principalmente por conta de alterações significativas que estão ocorrendo em sua estrutura, através de mudanças nas políticas públicas educacionais, atingindo diretamente a própria função do professor na escola.

Desse modo, as discussões sobre a valorização docente dentro do contexto das políticas públicas do Brasil são necessárias, pois o trabalho do professor vem sendo reorientado segundo as determinações de políticas de cunho neoliberal, "numa lógica voltada para a flexibilização, eficácia e avaliação dos resultados e desempenhos". (LIRA, 2013, p. 64).

Assim, o objetivo deste texto é discutir acerca da desvalorização dos professores da educação básica, no Brasil, a partir de uma análise das condições de trabalho docente, os antecedentes históricos, o arcabouço legal e as influências do neoliberalismo nas políticas de Estado. 


\section{Condições de trabalho docente no Brasil: história e legislação}

De acordo com Sant'Ana (2010), a educação brasileira vem sofrendo reformas desde os anos 1960 do século XX, tendo como objetivos, na época, expandir o acesso do maior número de pessoas à escolaridade, que, à época, já era compreendida como o caminho mais eficiente e seguro para a ascensão social das famílias menos favorecidas e também uma aproximação às exigências do modo de produção fordista. Essa situação criou alterações importantes nas condições de trabalho dos professores, como é explicado por Monlevade (2000):

O professor - operário, no meio de uma avassaladora inclusão de milhões de matrículas nos sistemas escolares primário e secundário, de 1950 a 1980, dobrou e até triplicou sua jornada, por pressão da demanda e/ou necessidade de sobrevivência. Este novo regime de trabalho impossibilitou, definitivamente, qualquer dedicação em preparar suas aulas e avaliar a produção dos alunos, cada vez mais numerosos (MONLEVADE, 2000, p.63).

Segundo Souza (2011), com o fim do governo militar em 1985 e a abertura democrática no país, ocorreram avanços na valorização docente, pelo menos do ponto de vista jurídico. A Constituição Federal de 1988, no seu artigo 206, inciso V e VIII, apresenta elementos de valorização docente:

V- valorização dos profissionais da educação escolar, garantidos, na forma da lei, planos de carreira, com ingresso exclusivamente por concurso público de provas e títulos, aos das redes públicas; (...)

VIII - piso salarial profissional nacional para os profissionais da educação escolar pública, nos termos de lei federal (BRASIL, 1999).

A Lei no. 9.394/96, também conhecida mais comumente como Lei de Diretrizes e Bases da Educação (LDB), em seu artigo 67, ratifica os dados apresentados pela Constituição Federal, ao apresentar os elementos fundamentais que devem ser observados pelos sistemas de ensino, no sentido de promover a valorização dos profissionais de educação:

Os sistemas de ensino promoverão a valorização dos profissionais da educação, assegurando-lhes, inclusive nos termos dos estatutos e dos planos de carreira do magistério público:

I - ingresso exclusivamente por concurso público de provas e títulos; 
II - aperfeiçoamento profissional continuado, inclusive com licenciamento periódico remunerado para esse fim;

III - piso salarial profissional;

IV - progressão funcional baseada na titulação ou habilitação, e na avaliação do desempenho;

V - período reservado a estudos, planejamento e avaliação, incluído na carga de trabalho;

VI - condições adequadas de trabalho. (BRASIL, LDB. Lei n 9394/96).

Apesar do arcabouço legal, representados pela Constituição brasileira de 1988 e a Lei de Diretrizes e Bases da Educação (LDB), enquadrarem a educação como um direito fundamental, o governo brasileiro, através dos processos de flexibilização das condições de trabalho docente e mercantilização do ensino, começou gradativamente a abrir mão do seu compromisso com a educação em favor da privatização do ensino (OLIVEIRA; PIRES, 2014).

Mancebo (2007, p. 468) comenta sobre o processo de neoliberalismo na América Latina e como isso influencia nas políticas públicas referentes aos direitos fundamentais, como a educação:

A adoção das políticas neoliberais, como programa de vários governos, não ocorreu simultaneamente, nem seguiu a mesma trajetória em todos os países, no entanto, durante os últimos 20 anos, o Brasil, bem como os países da América Latina, tem passado por processos de reforma, com base na racionalização do gasto público e redefinição das modalidades de intervenção do Estado, acarretando profundas mudanças em suas estruturas econômicas e sociais.

Santos (2013) enfatiza que, sob a ideia de melhoria da qualidade da educação, várias ações governamentais foram sendo implementadas, com vistas a "diagnosticar" os problemas educacionais do país:

No contexto das medidas voltadas à promoção da qualidade da educação, a partir da década de 1980 manifestaram-se as primeiras iniciativas por parte do MEC no sentido de implantar sistemas centralizados de avaliação da educação no País, com a finalidade de detectar os problemas incidentes no ensino, definir ações para corrigi-los e subsidiar a formulação de políticas educacionais. Neste sentido, foi instituído o Sistema de Avaliação da Educação Básica (1990), o Exame Nacional do Ensino Médio (Enem) (1998), o Exame Nacional de Cursos (Provão) (1995) posteriormente transformado em Exame Nacional de Desempenho de Estudantes (Enade) (2004) e que passou a integrar o Sistema Nacional de Avaliação da Educação Superior (Sinaes) (p. 76). 
A partir dos anos 1990 do século XX, com a ascensão das políticas públicas com base no neoliberalismo e a reconfiguração do papel do Estado e sua consequente reestruturação produtiva, que provocaram alterações no mundo do trabalho, as reformas educacionais no país se intensificaram, impactando diretamente no campo educacional (SANT'ANA, 2010; LIRA, 2013). Concordando com os autores, Assunção e Oliveira (2009, p. 367) explicam que:

(...) o processo de intensificação do trabalho vivido pelos docentes das escolas públicas brasileiras na atualidade pode, além de comprometer a saúde desses trabalhadores, pôr em risco a qualidade da educação e os fins últimos da escola (...).

Com a desculpa da racionalização do Estado e a compreensão da educação como custo e não como investimento, as políticas de cunho neoliberal acabaram por fazer com que as condições de trabalho do professor entrassem em franco declínio, tanto pela desvalorização da profissão por conta do achatamento salarial quanto pela criação de novas funções docentes na escola, como é esclarecido por Assunção e Oliveira (2009, p. 361):

Executar outras tarefas durante o curso da ação principal, atender o aluno individualmente e controlar a turma coletivamente e preencher múltiplos instrumentos e formulários de controle são dimensões da intensificação do trabalho que implicam regular com urgência. Situações de sobreposição de tarefas podem explicar o cansaço físico, vocal e mental do docente.

Segundo Abicalil (2007), a baixa remuneração do professor, principalmente os que trabalham na educação básica, gerou uma série de abandonos de docentes, que procuraram outras áreas de atividades que apresentam, em média, ganhos financeiros maiores com formação equivalente.

Além disso, os cursos de licenciatura também estão sofrendo com a baixa procura por parte dos egressos do ensino médio e do aumento do número de abandono de alunos, gerando uma série de vagas ociosas que muitas vezes não conseguem ser posteriormente preenchidas.

Isso gerou uma situação inusitada, como esclarecem Mazzeto e Carneiro (2002), ao citarem o censo da educação nacional, pois o Brasil ainda carece de formar professores, haja vista que "faltam professores qualificados para dar aulas no ensino fundamental e no 
ensino médio. Cerca de 825 mil professores desses dois níveis de ensino não possuem formação superior" (p. 1207).

Um estudo feito por Adachi (2009) sobre a evasão de alunos dos cursos de licenciatura na Universidade Federal de Minas Gerais (UFMG) descobriu que, para além do salário, outros elementos também contribuíram para essa evasão, entre eles o baixo prestígio da profissão:

Baixo prestígio da profissão, baixos salários, dificuldades financeiras dos estudantes para permanecerem no campus, qualidade pedagógica dos docentes, pouca atratividade dos cursos, currículos inchados, repetitivos e desarticulados, distanciamento entre teoria e prática, matematicidade dos cursos, baixa qualidade do ensino médio - que contribuem para a mobilidade, se não para a exclusão e, por isso, precisam ser adequadamente trabalhadas (ADACHI, 2009, p. 61).

Entretanto, Monlevade (2000) entende que, apesar do salário não ser determinante para a valorização, ele expressa um determinado grau de valorização e o sustenta materialmente. Acerca dessa situação, Barbosa (2011) fez um estudo sobre os impactos do salário docente e concluiu que:

(...) a principal consequência dos baixos salários é a queda na qualidade da educação, posto que a docência exige tempo extraclasse para a realização de tarefas como preparação das aulas, correção das provas e atividades dos alunos as quais, por sua vez, ficariam comprometidas devido à jornada maior de trabalho que o professor, muitas vezes, assume para compensação salarial (BARBOSA, 2011, p. 125).

O Anuário Brasileiro da Educação Básica, em sua edição de 2017, apresenta dados comparativos entre a média salarial dos professores da educação básica e profissionais de outras áreas. Os dados mais atuais são referentes a 2015 e podem ser vistos na tabela 1:

Tabela 1: Rendimento médio dos professores da educação básica e de profissionais de outras áreas com curso superior no ano de 2015

\begin{tabular}{|l|c|}
\hline \multicolumn{1}{|c|}{ Áreas } & Valor médio em \\
& $\mathbf{2 0 1 5}$ \\
\hline Professores da educação básica & $\mathrm{R} \$ 3.846,39$ \\
\hline Profissionais da área de exatas & $\mathrm{R} \$ 12.300,57$ \\
\hline Profissionais de humanas & $\mathrm{R} \$ 8.313,15$ \\
\hline Profissionais de saúde & $\mathrm{R} \$ 7.821,82$ \\
\hline
\end{tabular}


SILVA, O. O. N. da; MIRANDA, T. G; BORDAS, M. A.G. Condições de trabalho docente no Brasil: ensaio sobre a desvalorização na educação básica

\begin{tabular}{|l|c|}
\hline \hline $\begin{array}{l}\text { Média do rendimento dos profissionais com curso superior } \\
\text { (exceto professores da rede pública) }\end{array}$ & $\mathrm{R} \$ 7.325,14$ \\
\hline $\begin{array}{l}\text { Proporção da média salarial dos professores em relação à } \\
\text { média dos profissionais com curso superior (em \%) }\end{array}$ & 52,5 \\
\hline
\end{tabular}

Adaptado do Anuário Brasileiro da Educação Básica (BRASIL, 2017)

É possível perceber o abismo que separa os professores de educação básica dos outros profissionais com nível superior, chegando a 52,5\% de defasagem em relação à média, mas com uma diferença muito maior se comparado com a média salarial dos profissionais da área de exatas, por exemplo. Esses achados vêm a corroborar com os estudos de Adachi (2009) e a confirmar o pensamento Monlevade (2000), afastando ainda mais os jovens da docência.

Entretanto, é importante esclarecer que alguns autores, como Hirata e seus colaboradores (2019), acreditam que um comparativo do salário dos professores com outras profissionais deve ser feito com cautela, haja vista as características inerentes ao trabalho de cada profissão:

Comparar salários de docentes com os de outras ocupações é problemático, por várias razões: a forma de contratação por turnos, a diferença entre horas contratadas e horas docentes, a quantidade de dias efetivamente trabalhados por ano, a definição do que seja o trabalho real - por exemplo, tempo de estudo, planejamento, correção de deveres escolares ou outras atividades na escola. Também entram na equação as características do trabalho, especialmente a aposentadoria especial, a duração do ano letivo e o número de horas por dia fora de casa. Ademais, comparações, levando em conta o salário-hora, semanal ou anual, certamente resultam em conclusões diferentes (HIRATA et al, 2019, p. 189).

Juntamente com a desvalorização salarial, o trabalho docente vem sofrendo ao longo do tempo diferentes ataques em sua estrutura, com profundas mudanças para a categoria, sob a ótica neoliberal de controle de qualidade e reestruturação produtiva, assimilado para dentro dos estados, obrigando os docentes a desempenharem funções que vão muito além do ato de ensinar (LIRA, 2013). Ideia também corroborada por Tostes et al (2018):

(...) somam o aumento dos contratos temporários e a perda de garantias trabalhistas; falta de preparo durante a formação; dificuldades na relação com alunos e pais, diante das fragilidades da escola; exigência de adoção 
de uma pedagogia que não corresponde ao modelo de escola instituído; cumprimento de várias jornadas em diferentes escolas, sobrecarga advinda da assunção de tarefas como preenchimento de relatórios, cálculo de notas e anotações de frequência. Ao lado disso, aprofunda-se a cobrança sobre os professores diante do aparente fracasso da escola, ocultando a contradição por eles sofrida através da exigência de qualidade em um ensino que atendendo a um sistema de massa, com alta competitividade e recursos precários, em uma conjuntura na qual a escolaridade não é garantia de emprego (p. 89).

De acordo com Santos (2013), os apoiadores do uso dos princípios da gestão empresarial, de "qualidade total", em todos os aspectos organizacionais e humanos da administração pública da educação, acreditam que podem contribuir de maneira significativa para a melhoria do ensino no Brasil.

Entretanto, sob o véu de uma administração mais eficiente com os gastos públicos, esses mesmos estados adotaram modelos de gestão que visam alterar o gerenciamento da educação, como se a escola fosse uma empresa e os alunos clientes, como explicado por Freitas (2012, p. 91),

A crítica às reformas (...) aponta que, em consonância com o modelo de ajuste neoliberal, prevaleceram, no período, políticas centradas na gestão, eficiência, gerência e de redução do papel do Estado, à revelia dos professores, atribuindo seu fracasso ao baixo protagonismo dos professores em sua implementação, produzindo, segundo essa ótica, a perpetuação das desigualdades, do baixo rendimento dos alunos e a repetência e o abandono da escola.

Essa reestruturação da carreira docente e sua consequente precarização afeta não só a escola, mas todo o sistema educacional, haja vista que acaba repercutindo em mudanças profundas na natureza do trabalho escolar e a carreira do magistério, além de atacarem diretamente conquistas históricas da categoria, ao propor reduzir direitos trabalhistas e salariais.

Isso tem forçado os professores a acumular duas ou três jornadas de trabalho, com o intuito de melhorar sua remuneração, o que pode acarretar em problemas físicos, psicológicos, além da diminuição na qualidade dos serviços prestados à comunidade (LIRA, 2013).

O problema da desvalorização da profissão docente, em especial por conta da desvalorização das condições de trabalho, que ocorre dentro do padrão neoliberal, vem 
acometendo em menor ou maior grau diversos países nos últimos anos (UNESCO, 2005;

BASTOS, 2016; BOUKOU, 2017; TOH, 2017).

(...) en dépit de quelques initiatives non moins importantes dans l'amélioration des conditions de vie et de travail du personnel enseignant, les observations indiquent que les efets de ces politiques semblent se traduire par descontraintes qui surplombent encore la profession enseignante et le système éducatif ivoirien dans son entièreté. La présente contribution indique que la précarité de la profession enseignante s'est accentuée, mais surtout que cette profession a été déstabilisée, car ayant perdu ses repères. (...) dans le domaine de l'éducation, tout laisse à penser et à croire que les institutions fnancières internationales visaient autre chose que l'amélioration du système éducatif. En tout état de cause, les conséquences de cette dégradation et de cette précarisation de la profession enseignante sont énormes (...). C'est pourquoi il est important de lancer d'autres mesures pour répondre efficacement et durablement aux impacts sociaux, économiques et culturels des réformes internationales, et non proposer des réponses qui continuent de plonger la profession enseignante dans une précarité (...). ${ }^{4}$ (TOH, 2017, p. 32-33).

É notório perceber a mudança de paradigma da educação, outrora encarada como direito imutável e fundamental do ser humano e dever do Estado para com seu povo, foi aos poucos transformada em um serviço que pode simplesmente ser terceirizado e regulado pelo mercado.

De acordo com Cury Junior (2006), o professor acabou tendo seu tempo livre cada vez mais engolido pelas atribuições que lhe são imputadas, diminuindo, assim, o tempo destinado ao lazer, aos familiares, aos estudos, ao aprimoramento e à qualificação profissional:

Tantas são suas tarefas no dia a dia e em praticamente todos os dias da semana, além de todos os efeitos complementares da "contaminação" crescente da sua vida pelo trabalho e pela escola que permanecem nele "colados" de tal forma que deles não consegue esquecer, mesmo que queira (p. 4).

\footnotetext{
${ }^{4}(\ldots)$ apesar de algumas iniciativas importantes para melhorar as condições de vida e de trabalho dos professores, as observações indicam que os efeitos dessas políticas parecem se refletir ainda na profissão docente e no sistema de educação marfinense em sua totalidade. Esta contribuição indica que a precariedade da profissão docente aumentou, mas acima de tudo que esta profissão foi desestabilizada porque perdeu o rumo. (...) no campo da educação, há todas as razões para acreditar que as instituições financeiras internacionais visam algo diferente de melhorar o sistema educacional. De qualquer forma, as consequências dessa deterioração e precariedade da profissão docente são enormes (...). É por isso que é importante lançar outras medidas para responder de forma eficiente e sustentável aos impactos sociais, econômicos e culturais das reformas internacionais, e não propor respostas que continuem a mergulhar a profissão docente na precariedade (Tradução nossa).
} 
Concordando com essa ideia, Vasquez-Menezes e seus colaboradores (1999) também relacionam a questão entre a deterioração das condições de trabalho docente, gerando a ampliação da carga horária de trabalho para tentar enfrentar o achatamento de salários, não só com a diminuição do tempo livre, mas também com diversos problemas de saúde, tanto físico quanto psíquicos:

Se de um lado a necessidade de trabalhar, de outro a necessidade de se dedicar mais à família, à vida cotidiana com a casa, os filhos, o marido, as obrigações... Enfim, um conflito instalado, um paradoxo, uma angústia. A atividade profissional exige também um trabalho fora da escola. Ler, corrigir prova, preparar aula, se atualizar. Atividades inerentes à função. Essa é a vida do professor, é exercer uma missão de tempo integral. 0 envolvimento pessoal no trabalho continua e tem que continuar cada vez mais intenso, é a sua proposta de vida. Mas, e a família? 0 resultado disso tudo não poderia ser outro, um sofrimento psíquico, a exaustão emocional e a despersonalização (VASQUES-MENEZES et al, 1999 p. 281).

De acordo com Tostes e seus colaboradores (2018), essa excessiva carga horária laboral que os docentes acabam fazendo para além daquela realizada nas escolas é a materialização de um agravamento das condições de trabalho dos professores que gera, portanto, a gradativa desvalorização da profissão perante a sociedade e em comparação com outras profissões.

Ainda segundo o argumento dos mesmos autores, a "desvalorização do trabalho do professor se traduz pelo desrespeito por parte dos alunos, baixos salários, carga de trabalho exaustiva, alto número de alunos por classe e pressão por metas de produtividade, fatores responsáveis pelo intenso sofrimento docente" (TOSTES et al, 2018, p. 89).

\section{Considerações finais}

Aqui retomamos o objetivo do artigo que foi fazer uma discussão sobre a desvalorização dos docentes brasileiros que trabalham na educação básica, a partir de uma análise das condições de trabalho dos professores, focando nos precedentes históricos, no arcabouço legislativo e no efeito da influência do neoliberalismo nas políticas públicas governamentais. 
SILVA, O. O. N. da; MIRANDA, T. G; BORDAS, M. A.G. Condições de trabalho docente no Brasil: ensaio sobre a desvalorização na educação básica

O que podemos observar nas discussões com os autores e os dados apresentados é que existe uma defasagem entre o salário dos professores da educação básica no Brasil e a média dos profissionais das outras áreas.

Além disso, foi possível inferir que existe uma relação direta entre a qualidade do salário dos professores e sua valorização perante a sociedade, gerando efeitos psicossociais positivos para ele, como satisfação, motivação e consequentemente afetando diretamente na qualidade do trabalho executado e na melhoria da educação de forma geral.

Há notáveis avanços na legislação educacional brasileira, com vistas à valorização do magistério e discussões sobre como fazer essa valorização, em que sempre o salário entra na discussão como elemento central, pois de acordo com o estudo de Lira (2013) uma boa remuneração para o professor pode ser, além da elevação do status social da profissão, uma importante condição de atratividade e continuação dos jovens na carreira do magistério.

Porém, o mesmo autor alerta que existem outros elementos que precisam estar presentes nas pautas de reivindicações da categoria dos professores, tais como uma atenção a formação inicial e continuada, plano de carreira, saúde docente e condições de trabalho satisfatórias (LIRA, 2013).

Assim, os professores e entidades representativas devem manter a reivindicação da continua valorização profissional perante a sociedade, resgatando o interesse que outrora existia nos jovens em ser professor.

Paralelamente é importante que mais textos acadêmicos como este precisam ser produzidos, inclusive com estudos de campo, por se tratar de um tema de extrema relevância para o desenvolvimento de qualquer nação.

\section{Referências}

ABICALIL, Carlos Augusto. Piso Salarial: constitucional, legítimo, fundamental. Revista Retratos da Escola, Brasília, v. 2, n. 2-3, p. 67-80, jan./dez. 2008.

ADACHI, Ana Amélia Chaves Teixeira. Evasão e evadidos nos cursos de graduação da UFMG. 2009. 214 p. Dissertação (Mestrado em Educação). Universidade Federal de Minas Gerais. Belo Horizonte.

ASSUNÇÃO, Ada Ávila; OLIVEIRA, Dalila Andrade. Intensificação do trabalho e saúde dos professores. Educação e Sociedade. vol. 30, n. 107, pp. 349-372, maio/ago. 2009. 
SILVA, O. O. N. da; MIRANDA, T. G; BORDAS, M. A.G. Condições de trabalho docente no Brasil: ensaio sobre a desvalorização na educação básica

BARBOSA, Andreza. Os salários dos professores brasileiros: implicações para o trabalho docente. 2011. 208 p. Tese (Doutorado em Educação Escolar) - Faculdade de Ciências e Letras, Universidade Estadual Paulista, Araraquara.

BASTOS, Remo Moreira Brito. Sistema Educacional Cubano: fatores explicativos e reprodutibilidade em outras formações sociais. Cadernos de Pesquisa: pensamento educacional. Curitiba, vol. 11, nํ 27, janeiro-abril de 2016. p. 34-62.

BOUKOU, Jean Claude. Identites Professionnelles des Enseignant(e)s: Analyse des Situations et études comparatives entre le Congo-Brazzaville et le Congo-

Kinshasa. 2017. 338 p. Thèse (Doctorat en Sociologie du travail) Conservatoire National des Arts et Métiers. Paris.

BRASIL. Anuário Brasileiro da Educação Básica 2017. São Paulo, Editora Moderna, 2017.

BRASIL. Constituição da República Federativa do Brasil. São Paulo: Saraiva 1999.

BRASIL. Lei №. 9.394, de 20 de dezembro de 1996. Estabelece as Diretrizes e Bases da Educação Nacional.

CARMO, Jefferson Carriello do. Considerações Sobre Processo de Produção Capitalista e a Precarização do Trabalho Docente na Escola. Quaestio: revista de estudos em educação, [S.l.], v. 12, n. 1, set. 2010.

CURY JÚNIOR, Célio Hely. A formação docente como estratégia de superação do precarizado trabalho docente. Revista Profissão Docente, Uberaba, v.6, n. 14, p. 67- 76, out/dez. 2006

FREITAS, Helena Costa Lopes de. Formação inicial e continuada: a prioridade ainda postergada. In: OLIVEIRA, Dalila Andrade; VIEIRA, Livia Maria Fraga (Org.). Trabalho na educação básica: a condição docente em sete estados brasileiros. Belo Horizonte: Fino Traço, 2012.

HIRATA, Guilherme; OLIVEIRA, João Batista Araújo e; MEREB, Talita de Moraes. Professores: quem são, onde trabalham, quanto ganham. Ensaio: Avaliação e Políticas Públicas em Educação. Rio de Janeiro, v. 27, n. 102, p. 179-203, Mar. 2019.

LANCILLOTTI, Samira Saad Pulchério. Transformações Históricas do Processo de Trabalho Docente. Quaestio: revista de estudos em educação, [S.l.], v. 12, n. 1, set. 2010.

LIRA, Ildo Salvino de. A desvalorização do trabalhador docente brasileiro: o que dizem os documentos oficiais? Revista Profissão Docente. Uberaba, v. 13, n.29, p. 63-72, jul. dez, 2013.

MANCEBO, Deise. Agenda de pesquisa e opções teórico-metodológicas nas investigações sobre trabalho docente. Educação e Sociedade. Campinas, vol. 28, n. 99, p. 466-482, maio/ago. 2007. 
MONLEVADE, João Antônio Cabral de. Valorização salarial dos professores: o papel do piso salarial profissional nacional como instrumento de valorização dos professores da educação pública básica. 2000, 307 p. Tese (Doutorado em Educação), Universidade Estadual de Campinas, Campinas.

OLIVEIRA, Lourival José de, PIRES, Ana Paula Vicente. Da precarização do trabalho docente no Brasil e o processo de reestruturação produtiva. Revista do direito público, Londrina, v.9, n.1, p.73-100, jan./abr.2014

SANT'ANA, Raquel Santos (Orgs.); LOURENÇO, Edvânia; NAVARRO, Vera, BERTANI, Iris; SILVA, José F.S. da. 0 Avesso do Trabalho II. 1.ed. São Paulo: Expressão Popular, 2010.

SANTOS, Betisabel Vilar de Jesus. Qualidade da educação: consensos e dissensos entre o discurso oficial e dos seus críticos. Interfaces Científicas - Educação, Aracaju, v.2, n.1, p. 71-81, out. 2013

SOUZA, Maria Verônica de. Profissão docente: história, condições de trabalho e questão salarial. Anais do 5 seminário nacional estado e políticas sociais. Unioeste, Cascavel. 9 a 12 de outubro de 2011.

TOH, Alain. Précarisation de la profession enseignante au primaire en Côte d'Ivoire.

Formation et profession, 25(2), 20-34. 2017

TOSTES, Maiza Vaz et al. Sofrimento mental de professores do ensino público. Saúde debate, Rio de Janeiro, v. 42, n. 116, p. 87-99, jan. 2018.

UNESCO - Organização das Nações Unidas para a Educação, a Ciência e a Cultura.

Condiciones de trabajo y salud docente: estudios de casos em Argentina, Chile, Ecuador, México, Perú y Uruguay. Santiago de Chile: Oficina Regional de Educação para a América Latina e Caribe (OREALC), 2005.

VASQUES-MENEZES, I.; CODO, W.; MEDEIROS, L. O conflito entre o trabalho e a família e o sofrimento psíquico. In: CODO, W. (coord.). Educação: carinho e trabalho. PetrópolisRJ: Editora Vozes, 1999. 

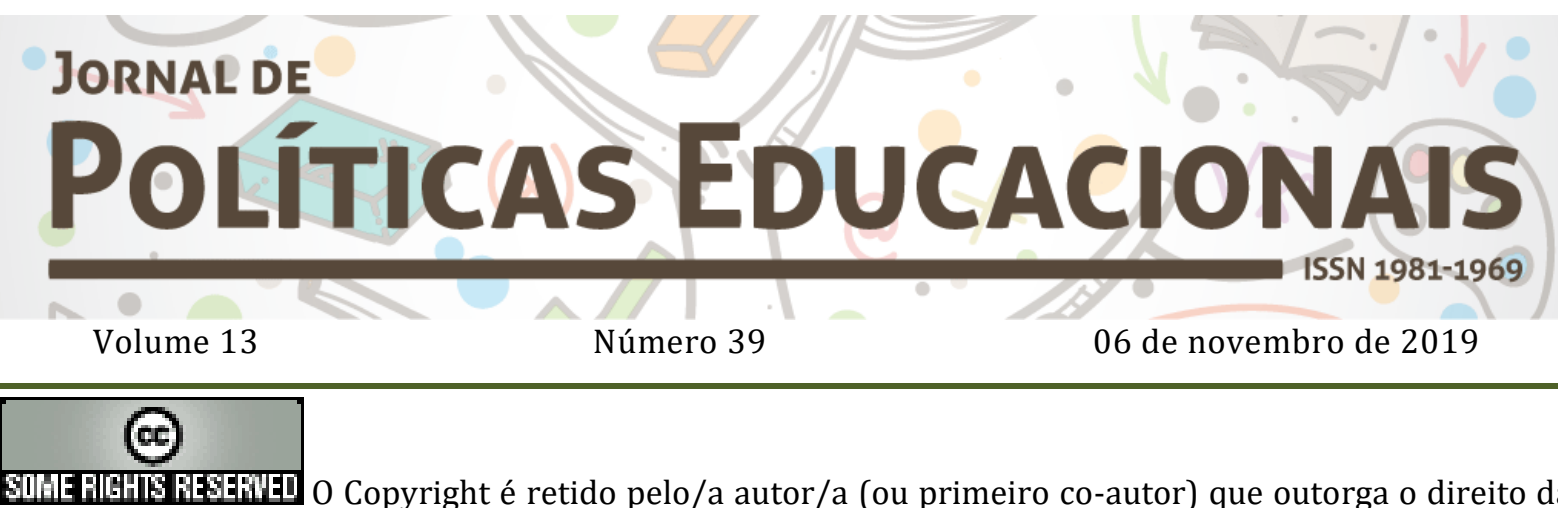
primeira publicação ao Jornal de Políticas Educacionais. Mais informação da licença de Creative Commons encontram-se em http://creativecommons.org/licenses/by-nc-nd/2.5. Qualquer outro uso deve ser aprovado em conjunto pelo/s autor/es e pelo periódico.

JoRnAL DE Políticas EdUCACIONAIS é uma publicação do Núcleo de Políticas Educacionais do Setor de Educação da Universidade Federal do Paraná - NuPE/UFPR, em consórcio com a Linha de Pesquisa em Políticas Educacionais do Programa de Pós-Graduação em Educação - PPGE/UFPR, que aceita colaboração, reservando-se o direito de publicar ou não o material espontaneamente enviado à redação. As colaborações devem ser enviadas ao NuPE/UFPR, conforme orientações contidas nas páginas do periódico na internet: http://revistas.ufpr.br/jpe.

\author{
Indexação: \\ BBE - Biblioteca Brasileira de Educação (MEC/INEP) \\ Clase (Base de Datos Bibliográfica de Revistas de Ciencias Sociales y Humanidades) \\ Diadorim - Diretório de Política de Acesso Aberto das Revistas Científicas Brasileiras (IBICT) \\ Google Scholar \\ Index Copernicus \\ Portal de Periódicos (CAPES) \\ SER - Sistema Eletrônico de Revistas da Universidade Federal do Paraná (SER/UFPR) \\ Sumários de Revistas Brasileiras (FUNPEC-RP) \\ DRJI - Directory of Research Journals Indexing
}

(Periódico integralmente disponível apenas em via eletrônica)

Jornal de Políticas Educacionais / Núcleo de Políticas Educacionais da Universidade Federal do Paraná -

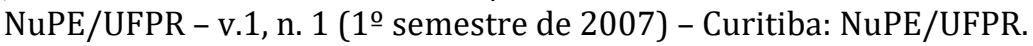

Volume 13, número 39 - Novembro de 2019

ISSN 1981-1969

1. Educação - Periódicos. 2. Política Educacional - Periódicos. I. NuPE/UFPR

Comitê Editorial:

Elisângela Scaff (UFPR)

Daniela Oliveira Pires (UFPR)

Conselho Editorial:

Andréa Barbosa Gouveia (UFPR - Brasil), Cesar Tello (Universidad Nacional Tres Febrero, Argentina), Fernanda Saforcada (Universidad de Buenos Aires - UBA - Argentina), Gladys Beatriz Barreyro (USP Brasil), Gustavo Enrique Fischman, (Arizona State University - USA), Jefferson Mainardes (UEPG - Brasil), João Ferreira de Oliveira (UFG - Brasil), Juca Gil (UFRGS - Brasil), Luiz Souza Júnior (UFPB - Brasil), Ney 
SILVA, O. O. N. da; MIRANDA, T. G; BORDAS, M. A.G. Condições de trabalho docente no Brasil: ensaio sobre a desvalorização na educação básica

Cristina Monteiro de Oliveira (UFPA - Brasil), Nicolás Bentancur, (Universidad de la República de Uruguay), Robert Verhine (UFBA - Brasil), Rosana Cruz (UFPI - Brasil), Rubens Barbosa Camargo (USP - Brasil), Sebastián Donoso Díaz (Universidad de Talca - Chile), TheresaAdrião (UNICAMP - Brasil), Vera Peroni (UFRGS - Brasil).

Créditos e Agradecimentos:

Revisão de Língua Portuguesa, Abstract e Resumen: PROGRAMA DE APOIO ÀS PUBLICAÇÕES CIENTÍFICAS PERIÓDICAS DA UFPR

Arte e diagramação: TIAGO TAVARES (iagotav@gmail.com)

\author{
Jornal de Políticas Educacionais \\ Universidade Federal do Paraná \\ Setor de Educação \\ Núcleo de Políticas Educacionais - NuPE/UFPR \\ Avenida Sete de Setembro, 2645 \\ 2o andar, Sala 213 \\ 80.230-010 - Curitiba - PR - Brasil \\ Tel.: 41-3535-6264 \\ jpe@ufpr.br \\ http://revistas.ufpr.br/jpe
}

